\title{
Phenomenology of Phantasy and Fiction: Some Remarks Towards a Unified Account
}

\author{
Pedro M. S. Alves \\ University of Lisbon \\ School of Arts and Humanities \\ Centre of Philosophy \\ Department of Philosophy \\ psalves2@gmail.com
}

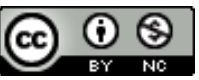

\begin{abstract}
I offer an outline of an integrated phenomenological analysis of free fantasy and of fictional worlds. My main concern amounts to stress the scissions entailed in free fantasy and in the consciousness of fictional objects: a scission of the I, and a scission of the experience. Firstly, I offer a somewhat new characterization of the presence of the objects of free fantasy, which disconnects any possible relationship of those objects with a real perception as the leading form of an originally giving consciousness. My leading example is daydream. Secondly, I take the Husserlian analysis of neutralization as a conceptual tool to explain the consciousness of fictional worlds, against a new tendency for interpreting these worlds in light of the concept of "possible world". The two approaches converge to a twofold characterization of the mode of being of fictions and of the modality of presence of the objects of fantasy.
\end{abstract}

Keywords: Husserlian Phenomenology, Phantasy, Fiction, Neutralization

In what follows, I will suggest that the phenomenological analysis of the modification of neutrality is an appropriate tool for understanding the mode of being of fictions. Before, I will suggest that the phenomenological analysis of free fantasy can throw light on the mode of presence of fictional objects.

Fictions are everywhere present in our cultural world. They are pre-given in it by means of stories that are told and shared, or in written words; they are even accessed through a modification of the perceptual world, as when we attend 
theater or see movies, or, in general, every time we built in the matter of perception the presence of an imaginary world. Fictional objects are not separated from the real world by means of a clear cutting-line. Rather, there is a permanent double-way movement between reality and fiction: fictions are built with the materials of the so-called actual world, and many times our senseapprehension of the actual world is framed by fictions. The intertwining of sense between reality and fiction is a constant phenomenon of our world experience.

Though, fictional objects are not simply pre-given in the cultural world. Instead, one of the most pervasive phenomena of our subjective life is the openness to a fictionalized world by means of fantasy. I am not referring to the activity of producing images that float before our eyes. These images can be referred to the actual world, as when we anticipate or remember real persons or events. Rather, I am referring to the active, deeply interested and attentive free construction of alternative stories of our own self, as in daydream and similar phenomena. This is not a matter of just seeing an image, but of building other stories of the world and of ourselves, in which images are simply evanescent illustrations of an underlying framework of sense. This is an almost solitary activity. However, it can also be an intersubjective relationship, like in children's plays of make-believe, or in the modern technologies of virtual reality, by means of avatars, and other forms of reinvention of our identity.

If I am putting these two phenomena - free fantasy in daydream and fictional stories - together, it is because there is an underlying close structural similarity between them, and, then, a remarkable difference. The similarity - which is, I suppose, an essential feature - is that both institute a scission of our egoic life. A scission of our experience, split in a double directness towards an actual world and towards a fictional world; and a scission of our self-experience, split in our own story according to the principles of reality and truth, and a free reinvention of alternative stories of our own self. Though, scissions are not abysses. There is always an ongoing synthesis of sense between both members. I believe that the concrete subjective life is thrown by this ongoing, never complete synthesis of sense.

Now, the remarkable difference regards the way the ego is present in them. Fantasy, for instance, in daydream, convokes the ego as the very center of the fantasized world. I am there, and the scenes are displayed from the point of 
view of my fantasized ego. On the contrary, in fictional stories, or even in seeing perceptual images like a portrait, the ego is certainly present, even present in the modes of attention and interest, but present in the form of an ego of observation: he is not a part of the fictional world that is before him.

I believe that a phenomenological analysis of the constitution of fictional objects is able to account for both the deep unity and the difference between these apparently disparate phenomena.

As I said before, I will focus on two important features of fictional consciousness. They are:

a) The way fantasy objects are present, and the subject to which they are present;

b) The way fictional stories posit a reality of its own, to which the ego is convoked as an observer assuming the form of an anonymous life.

I offer only an outline. I will discuss the first issue by means of a phenomenological clarification of fantasy based on Husserl's fundamental insights, and then through an analysis of daydream, as a paramount case of free reinvention of our identity. The second issue will be mostly addressed by means of the Husserlian theory of the modification of neutrality.

\section{Fantasy and the fantasized I}

For the issue of imagination, phenomenological analyses turn out to be a real liberation from some presuppositions that affect the naturalistic psychological approaches. Indeed, according to their sense, the objects of imagination are given not as internal to the mind, but as being there, before the act that is directed to them. They are not to be described as "internal" in some psychological sense. On the contrary, they are present as objects in an imaginary scene that faces the subject as something to which it has an intentional access.

It is not only the presupposition of the internality of the objects of imagination that is corrected by phenomenology, but also a defective way of characterizing their mode of presence or givenness. Indeed, we find even in Kant a standard conception of imagination as the "faculty of representing an 
object even without its presence in intuition" (Kant 1998, 256; B 151). Even though Kant highlights a kind of spontaneity of imagination and distinguishes it, as the productive imagination (die produktive Einbildungskraft), from the simply reproductive one, the fact remains that imagining is conceived as a form of having something in its absence. What is given trough imagination is, then, just a proxy of the object itself. The intuitive content of imagination substitutes the intuitive content of the presentation of the object, which is only attainable by means of a perception (Wahrnehmung). This is tantamount to conceiving imagination in the light of perception, as something that at last always refersback to it.

What if imagination was not always directed to a possible real perception? What if the objects of imagination were given with the sense of being directly there, for the imagining subject?

As it is well-known, Husserl began his study of fantasy putting it in the framework of a picture-like model. In his early texts, fantasy was accounted for as a kind of image-consciousness, a Bildbewußtsein, that is, as an indirect consciousness of something which is not present, by means of something that, in its intuitive presence, appears as substituting it and referring to it by means of a synthesis of similarity, precisely, as an icon or Bild. However, Husserl very soon realized that, according to the sense of the intentional acts, the objects of fantasy were given by themselves, not by means of a substituting, picture-like presentation. Thus, the separation between fantasy and image-consciousness. Indeed, when one imagines a Centaur, it is the Centaur itself that is given, it is directly present, although with the modification of unreality. This latter modification belongs to the thetic quality of the act, not to its intuitive content, which functions here as a presentation or exhibition of the very thing intended. In a strong sense, there is a direct, intuitive appearance of what does not exist (of what is intended as non-existent), a kind of phenomenon of unreality.

Now, regarding the connection between imagination and perception, the lessons of the phenomenological analyses are also instructive. Remembering, expecting, or imagining, while being all of them self-presentations of their objects, are affected by an overall modification. As Husserl has finally put it, they are a reproductive consciousness in a wide sense. Husserl captures this modification by means of the opposition between perception, as an originally presenting consciousness, a Gegenwärtigung, and a consciousness that does not 
originally present its object, being it directly given, as in fantasy, remembrance and expectation, or indirectly given, as in image-consciousness. Not considering image-consciousness, the modification regards the fact that an original consciousness of something is reproduced by another consciousness with several degrees of freedom. Being so, the object is not itself reproduced. Instead, what is reproduced is the "original" consciousness of it. Being brought about in their self-presence by means of a reproductive process, the object appears thus as modified. It is no longer self-given in a presentation, but instead self-given in a re-presentation or "presentification", a Vergegenwärtigung, which is the reproduction of a consciousness of something by another consciousness in the unity of internal time. As Husserl puts it, "'Reproduction' is the presentification of inner-consciousness, which stands in opposition to the originary course, to impression. The presentification of an objective process cannot be called reproduction. The event in nature is not reproduced once more; it is remembered, it stands before consciousness with the character of presentification" (Hua X, 128). Therefore, the famous formula: a reproduction (R) of a perception (W) of an object $a$ equals the presentification $(\mathrm{V})$ of $a$ : $\mathrm{R}\left(\mathrm{W}_{a}\right)=$ $\mathrm{V}_{a}$ (Hua XXIII, 311, and Hua X, 128).

Now, what is the specific reproductive link between free fantasy and perception? Has free fantasy always a back-reference to a possible, different act of perception, so that it always turns to be the presentation of an object in its absence?

Let us take a clear case of fantasy that is not mingled with memories or expectations of absent objects. Let us take a counter-factual situation of daydream. While being here, I now imagine myself walking on a paradisiac beach in the Pacific Ocean, seeing the sea and the blue sky, feeling the wind in my face and the warm water in my feet. I am almost there. The scene is lived as non-real, of course. But there is a kind of para-belief-in, which posits this fantastic world and this variation of myself. The ego is now split into the ego who continues to experience an actual world, and, on the other hand, the ego that imagines and posits the varied ego who is living in the fantasized world. Indeed, when I dwell in the fantastic world, the beliefs in an actual world and in a real self are not suspended, but their efficacy is somewhat diminished. If I immerse myself in the fantasized world, I am no longer attentive to and interested in the actual world that continues to be posited in an enduring 
believe-consciousness. In a sense, I am "lost" there, and I am absent-minded here.

Thus, if remembering and expecting are reproductions of a past, or of a possible future perception in the unity of a unique experience, free fantasy is the production of a course of unreal present perceptions for a fantasized I. It has an autonomy by its own. Being so, it is not referred to an independent, effective perception as its original pattern. On the contrary, it is the free construction of a perception and of a perceptive world that overlaps with the fantastic "reproduction" of it. The perception is embedded in the very reproduction that refers to it. For this reason, it unfolds as an unreal or quasiperceptual apprehension, as a perception in the mode of the "as if". As a result, the objects of free fantasy are not really absent, as we are told by the received view, even though, in their self-presence, they fail the criteria for bodily, physical constitution: the threefold constitution as a res temporalis, a res extensa, and a res materialis (see Hua III-1, 347-348). In a sense, they are all present in the world of fantasy to the fantasized I, because the perception to which fantasy refers-back lies inside the very actual act of fantasy and is brought about by it.

What about the subject that experiences a fantasized world? Indeed, there is no experience without a subject. This is a trivial assertion. But what is to be the subject of an experience, and then of a fictional experience? This is a somewhat embarrassing question. If relevant, the answer will no longer be a trivial one.

Subjectivity is wider than egoity. Plenty of lived-processes arise and fade away without being noticed by the I. They form an all-embracing framework where intentional activity begins. They are not unified: the several sensible fields, the emotional sphere, the drives of the will, and other dimensions of subjective life, run their course parallelly, without a unification pole. As such, they belong to a stratum that phenomenology names "passivity". By themselves, they have neither an ego-form, nor an intentional relationship to something.

Now, for a lived-process, what is to be noticed? I suppose that a bad answer would be: to be noticed is to be caught by the ego. A bad one because the phenomenon we name "being noticed" is the very genetic "birth" of an ego from the depths of passive life. Indeed, "being noticed" is at the very thresholds of the form-ego in what regards perceptual life. The ego was not there before, 
that is, when one abstractively considers the passive fields as such. Genetic phenomenology describes this first entering of the ego-from by means of the descriptive concepts of affection, turning-towards, attention, and interest. They trigger objectual constitution by means of a "capture" (Erfassung), and then a perception (Wahrnehmung) of something. They all belong to the stratum of receptive life. However, it is not the case that an ego, whatever it is, was lurking there and suddenly comes to be "affected". On the contrary, some contents (say, a blotch of color, an emotion, a drive of the will) become the center for a reorganization of the passive fields (Husserl calls it the phenomena of prominence and contrast, Abgehobenheit, and Kontrast, while maintaining an ambiguity as to whether they belong to passivity or to receptive affection). This determines that some other passive data are caught and mingled with them by a synthesis of attunement, while others fade and completely disappear in the dark, even without a retentional "tail" (the "de-filling" or emptying of the living-present, which Fink names "Entfüllung"). Thus, regarding perception, the activity with which the ego starts is closely tied to phenomena which have not an ego-form.

It is this reorganization, affectively joining together some passive data while excluding others, that brings about something like a "theme" of perceptual intentional life. From now on, there is something like a perceptual "act" (of the form-cogito), and an I who "lives" in it, appearing there as what Husserl calls a "ray" (Strahl) that has a "direction" (Richtung) to something through the forms of attention and interest, so that the I raises itself as the executor, or the doer of the act. The theme functions, then, as a motivational unity for new reorganizations of the passive background that go both to the immediate future and to the past. The receptive configuration of the passive fields that brings about a "theme" belongs to the cognitive, evaluative, or to the practical realms, depending on the passive data that become affectively dominant and that submit to them the others by syntheses of attunement. At this level, the intentional direction to something as object (perceptual, evaluative, etc.) mingles with the self-constitution of a somatic body (Leibkörper) that has a spatio-temporal orientation to the object from the "here" and the "now" where "I am".

Now, as in the case of daydream I referred above, free fantasy seems not to have a pre-condition in passivity. Indeed, the beach I fantasized was not already pre-given in the passive fields. Where does it come from? It is as if the ego of 
fantasy emerged by itself with all its elements, standing on its own feet without a passive genetic story.

It is true that there is not a passive, sensorial datum pre-given and an affection by which the ego raises itself. In fantasy, the contents of the reproduced perception are brought about by the very act of imagining. This is also the reason why the objects of fantasy are poor in intuitive content and evanescent. In a sense, what we see in them is only what we put into them. However, this does not preclude the existence of a passive genesis as such.

Truly, fantasy is never an uninterested and inattentive accomplishment. Nor is it something to which the ego is not turned-to. An unmotivated fantasy is not a fantasy at all. What prompts free fantasy, then? My tentative answer is that free fantasy, the free construction of a fantastic world in which $I$ am as its subject, as in the case of daydream, is driven by underlying desires and emotions endeavoring for an expression and a satisfaction. I believe these are the passive data that trigger the free construction of a fantastic scene in which I am present as an experiencing self. Indeed, the beach where I am, the scenes I imagine myself living there, give free course to real feelings, moods, and desires which come by these means to an expression. In a strong sense, fantasy is not having an illusory appearance, but rather the activity of making-visible the depths of affective and emotional life, of bringing them to light. Fantasy is, thus, a kind of hallucinatory power (disregarding the pathological sense). So, while free, daydream is not arbitrary at all. It is determined by the passive emotional life and brings it to a visible expression, where I, as imagining ego, observe myself, as fantasized ego, given form to emotions and to the objects of desire. Under the relationship between intention and fulfillment there is, then, a hidden, underlying relationship between desire and satisfaction. Fantasy in daydream (and in plenty other forms) is the hallucinatory transfiguration of desire. It is a means for a self-understanding of the ego's own subjective life. Thus, the activity of bringing about a Fantasized ego in a fantasized world is determined by the freedom of construction, the pulls of affective forces, and by the exhibition in a hallucinatory experience of the objects of satisfaction in an "as if" world where a projected I of fruition stands as its subject. This selfprojection under a self-variation is, in my sense, the underlying mechanism of free fantasy. 
Hence, the key for understanding how free fantasy comes about is the process of re-invention or "rethinking" of my own ego. This is a kind of scission. Husserl refers to it in a theoretical framework, which is not ours, when addressing the issue of free variation in eidetic seeing, and more precisely the grasping of the eidos-world (he calls this scission the Umdenken or Umfingieren of my own ego). However, inasmuch as it is not determined by the theoretical production of counter-factual trains of experience that constitute incompossible worlds, so that an eidos-world is finally grasped as an invariant, this self-scission of the ego in fantasy, motivated by the ego's desires and emotions, involves an ongoing synthesis integrating all the self-variations in a unitary sense for the ego's identity. What is it, then?

Acts of reproduction like remembering and expecting adjust themselves under the form of the unity of a life which is the experience of a unique actual world. Acts of fantasy involve another form of adjustment. If I now imagine myself walking along a beach at dawn, then the ego of fantasy, the subject of fruition of this fantastic world, that is me, but this "me" has no connection with the ego that is perceptively turned to the actual world. The beach fantasized, such as it is presentified with my fantasized ego there, is not part of the actual world, either present or past. So, the ego that lives in this world of fantasy has no connection with the real life of the ego and cannot be inserted into it. The experience of the sunrise by the sea does not belong to the effective life of the ego, it is not an element in the constitution of its identity along the lines of reality and truth. What happens is that I project myself into a fantasized world, and then I observe myself there, I look at me from the inside and the outside in a complex mix, because the fantasizing ego and the fantasized ego are the very same. Thus, the fantasized ego unifies itself with the real ego in a synthesis of sameness that is wider than the identity under the principles of reality and truth. In short, since the imagined I is catch as a variation of myself in the form of an ego of fruition, there is always a synthesis of sameness; however, this synthesis of sameness is larger than the identity built on the principles of truth and reality.

Thus, what I call the synthesis of sameness is broader than the constitution of a narrow personal identity according to the principles of reality and truth. In egological life, reproductive acts happen whose objects fit into a single stream of life that is a continuous experience of a unified and unique actual world. But acts of fantasy also occur in the very same stream, acts which constitute a 
complementary ego, or another possible form of the ego with other experiences and another story. Egological life constantly operates a synthesis between both. At times, the reproduced ego refers-back to the present ego in the unity of a story and a world perceptively posited as actual; at other times, the reproduced ego is in opposition to the present ego and the actual perceptive world: it is not at one with it, but forms with it a multitude of mutually exclusive stories. Subjective life is the unity of both dimensions and the constant transfer of meaning from one to the other. Life in fantasy is a life that gives free rein to emotional drives and desires. In this sense, subjective life is always broader than the narrow, strict identity that is produced according to the principle of truth. The sense of subjective life is the unity and intertwining of both stories. Roughly, one tells the ego what he truly is or has done, the other displays to the ego what it would like to have or to be, or to have been. Both, put together in unity by a synthesis of sameness, constitute the inner sense of subjectivity, both turned to reality and truth, and to a unbounded fruition in a fantasized, "unreal" world.

\section{Fictional objects and neutralization}

I come now to my last point: the ontological status of fictional worlds.

In the last decades, the study of fictionality embraced the notion of "possible worlds". Not considering its Leibnizian inceptions, the concept of possible worlds was developed in the second half of the 20th century to settle some issues in formal semantics, like the truth conditions of counterfactual statements, and of sentences modified by modal operators. Borrowing a concept developed in the framework of modal logic for exploring fictional worlds has several important advantages, according to the proponents of this new line of approach to fictionality.

Nevertheless, as Ruth Ronen as pointed out (Ronen 2005), to approach fictional worlds by means of the concept of possible worlds goes hand in hand with a certain uneasiness. Neither the two concepts overlap, nor a fictional world can be accounted for as a case of a possible world. Disregarding Lewis extravagant ontological thesis, which considers a possible world as a parallel world with its own actuality, the underlying insight is that a possible world is, as Kripke suggests, a "total way the world might have been, or states or histories 
of the entire world" (Kripke 1980, 18). This insight considers a possible world as a non-actualized state of affairs of the actual world, or as sets of possible states that did not have taken place. In a word, a possible world is a description of how things could have been in our unique actual world.

Now, it appears as highly counter-intuitive to account for a fictional world as a case of a possible world, that is, as a description of alternative, nonactualized states of the actual world. Firstly, because even though fictional worlds are related to the actual world, they are not always a description of alternative states of it. The traditional example of the dice game is worth considering. Each possible outcome represents a possible world within the actual world. While only one result is actualized, the others clearly are possible ways the world could have been. However, a fictional story is not such type of a description. It is better accounted for as a quasi-world, in which things happen that do not necessarily have a connecting point to a set of possible events in the actual world. Secondly, a possible world is under several constraints regarding consistency and possibility. However, fictional worlds can include impossible situations and characters, as well as contradictory events, like in Alice in the Wonderland, so that both the principle of minimal departure and the logical laws must be strongly relaxed for a fictional world to be considered in the light of the concept of a possible world.

In a nutshell, as Ruth Ronen stresses,

It seems that a fictional world can be considered a possible world only in a radically modified way. The analogy between fictional worlds and possible worlds must obey severe restrictions. Consequently, 'a possible world' can only be considered a metaphor for fictional existence. (Ronen 2005, 358)

The general problem is that fictional stories posit a world on its own. We have beliefs about it that can be true or false. Nevertheless, this world, that is posited, is not posited as a possible world. It is both something that includes beliefs, and which is, nevertheless, despite the beliefs we have about it, wholly considered as unreal, even though, like in Hercule Poirot's stories, for instance, it can display a strong similarity with the actual world. The point is to account for such a complex network of beliefs and counter-beliefs. Fictional worlds are 
not posited as possible. They are not an assumption we make, either. What is, then, the attitude that gives access to a fictional story? That is the question.

I believe that Husserl's concept of neutrality would induce a big step forward in the characterization of the status of fictional objects. The sections 109 to 117 of Ideas-I are a good guide to neutralization as an overall modification that can affect all forms of the sphere of belief. Husserl characterizes it as

a) A general modification,

b) That suppresses (aufhebt) or weakens (entkräftet) every primal belief or other doxic modality,

c) Though, not like negation, which affirms a not-being "that is again a being" (Hua III-1, 247).

The point with neutrality is not to substitute a doxic character by another, say belief by possibility, or possibility by assumption. Instead, neutrality conserves the doxic modality of each lived-process. It neither strikethrough (durchstreicht) the doxic element, nor produces (leistet) something new. It simply turns every intentional positing act and its correlated noema in a mere "thinking-of" of exactly the same object with the very same thetic character. The doxic element is conserved, but it is no longer productive. In the neutrality modification, it is turned into a "counter-image" or a "shadow" (Husserl's expressions) of the former act. In accordance, there is a serious believing, a serious doubting, a serious deeming-likely or deeming-possible, with its correlates: being, being doubtful, possible, and so on. Neutralization does not change the forms of the doxic positing, as Urdoxa, and the series of its possible modalizations. Instead, the partition is between seriously intending something in whatever modality of being and quasi- or "as if" intending and believing, in a parallel series reflecting the former under the general modification Husserl calls, in Active Syntheses, "playful consciousness" (spieleriches Bewusstsein). While conserved in all its elements, the noetic-noematic structure is overall modified: the perception becomes the mere thinking-of a perception, the perceptum becomes the thinking-of a perceptual being, the empty intending of something becomes the thinking-of an intending, and so on. The suppression or weakening that belongs to neutrality is, thus, a subtle modification, in which 
nothing is really changed unless the "seriousness" of the accomplishments of consciousness. As Husserl writes, "The positional characteristic becomes powerless. Now, the belief is no longer a serious belief, the supposing is not a serious supposing, the negation is not a serious negation. They are 'neutralized' belief, supposition, and negation." (Hua III-1, 248). Thus, Husserl stresses that the opposition between positionality (in a wide sense, encompassing both primal believe and doxic modalities, on the one hand, and actuality and potentiality, on the other) and neutrality crosses the whole sphere of consciousness, creating two parallel series: the acts and its corresponding "images" (Bilder) or "shadows" (Schatten).

Accordingly, several aspects are worth noting.

Firstly, there is a deep difference between simple neutralization and epoche. Indeed, the latter neutralizes the general thesis and delivers by this means a new realm of being, the transcendental purified consciousness, which is then posited as a sphere of absolute being. However, with the former simple neutralization, nothing is posited. The modification is "unproductive", as Husserl says. It ranges over all lived-processes and constitutes a whole realm which is, ideally, the counterpart of the intentional life of consciousness.

Secondly, the domain of neutralized lived-processes and its noematic correlates is, according to Husserl, "non-predicable". Indeed, where there is no real positum as the correlate of serious positing acts, there is nothing to affirm, to explain, or to entail. It is, then, a realm where there is no claim for a rational justification. It stays beyond the jurisdiction of reason, and "the question about reason and unreason makes no sense for neutralized noeses" and their corresponding noemata (Hua III-1, 249). They are simply there as they are: the fact does not refer-back to a reason, nor does it point ahead to a consequence. As a result, there is a freedom in neutralized consciousness that does not exist in positionality.

Thirdly, as Husserl also points out, neutralized lived-processes must not be always preceded by positional consciousness. They can arise by themselves, being modifications that were not preceded by any positional act whatever. As Husserl says, "We just must not think of it as a transforming operation attached to a preceding position. It can also be such occasionally. But it need not be" (Hua III-1, 252). So, while, according to an essential law, neutrality is a modification of positionality, this does not entail that neutralized consciousness 
simply reproduces the content of a former positional consciousness. Indeed, as a factual assertion, it will be doubtful to affirm that the course of positional acts is doubled by a course of neutral acts that reflects or mirrors it. The other way around, even admitting that every positional consciousness can always be turned into a neutral one that mirrors it, we must state that acts emerge that are neutralized from the very outset, without being preceded by a corresponding positional act. The series of neutrality parallels the series of positionality, they both have their proper contents, although, sometimes, a neutral content is brought about by means of a modification of a former positional content.

Finally - and this is my point - the divide between positionality and neutrality institutes a whole scission in experience. Husserl talks about a separation or division (Scheidung). It is the scission of experience I referred above. Some experiences are constitutive of being, they are positing acts that fall under the jurisdiction of reason. Some others are constitutive in a manner that stays beyond reason and that can be characterized as the faculty of imagining in a wide sense. They escape the logical and ontological criteria for the constitution of being. Their constitutive result is no longer a being, but instead what Husserl calls a Fiktum, and a fictional world with his corresponding fictionalized ego. In Active Syntheses, Husserl refers to the constitution of fictions as follows:

The correlates of fantasy are fictions, $[\ldots]$ the correlates of positionality are realities, supposed or true realities. [...] In fantasy, all is meant with the sign of the play, either non-being or being. On the other hand, fantasy has also its constitutive accomplishments. Namely, the counter-image of a thing proving itself seriously in experience $[\ldots]$ is a fiction that $[\ldots]$ produces precisely the image of a consistent being, the image of a truly existing thing. (Hua XXXI, 13) ${ }^{1}$

1 „Die Korrelate der Phantasie sind Fiktionen, "Phantasiebilder", die Korrelate der Positionalität sind Wirklichkeiten, vermeinte oder wahre Wirklichkeiten... In der Phantasie ist all das mit dem Vorzeichen des Spiels vermeint, Nichtsein wie Sein. Andrerseits hat auch die Phantasie ihre konstitutive Leistung. Nämlich das Gegenbild eines sich ernstlich in der Erfahrung ausweisenden Dinges ... ist ein Fiktum, dass ... eben das Bild eines einstimmigen Seins ergibt, das Bild eines wahrhaft seienden Dinges." Husserl, Aktive Synthesen, § 3. 
When giving examples of neutralized consciousness, Husserl mostly refers the cases of perceptual images and free fantasy. However, the scope of neutralization is universal. Every lived-process with its corresponding noema can assume the form of a neutralized lived-process, and this possibility encompasses the theoretical as well as the emotional fields of conscious life. It is not shrunk to intuitive, sensible acts. Instead, it spreads over all formations of meaning, even over symbolic or empty thought.

Now, I believe that this modification, which Husserl firstly described in its purity, separating it from others, like assumption (Annahme), is very well fitted for accounting for the kind of attitude we adopt when listening to or reading fictional stories. As a general thesis, I will say that it is by neutralized consciousness that we enter and dwell in a fictional world.

In fact, reading Oedipus Rex, for instance, we rightly believe that Oedipus killed Laius, that he did not know that he was his very father, that he married Iocasta, that he blinded himself when he eventually realized what he has done, and so on. We feel sorry for Oedipus misery. We live all of this as an ego of observation. We do not belong to the story, as in the free fantasizing of our own self. We simply live in it in the form of an observer that is engaged cognitively and emotionally: it is the scene that is terrifying, happy, wrong or right. The ego is not a cold observational ego: he enters and lives in the story under the form of an anonymous life. More than an onlooker, it is an in-looker, so to speak. Moreover, we accept without blinking all the logical and physical impossibilities of a story like Alice in Wonderland, without even questioning or rejecting what we are told about Alice and the other characters. There is a strangeness of course, it belongs to the reception of this particular fictional world, but the jurisdiction of reason is suspended, as Husserl rightly remarks. Despite of this, the beliefs, expectations, or feelings are pretty alive, but they are "gleichsam" beliefs, feelings, and expectations. They are there, but no entailments are made. In a word, they are neutralized.

In a nutshell, I will say that neutrality offers a response to the counterintuitive conception I referred above, according to which fiction is about a possible variation of our actual world. Certainly, fiction can be about the way things may have been. Suppose Hercule Poirot was a real person. So, his stories belong to a possible variation of our own world. However, things do not always have to be this way. There are fictional stories that do not fit as variations of 
the actual world. They put a closed world completely different from our own, where even impossibilities can arise. This is the paramount case of fictionality, in which the stories that imitate the actual world are just a particular case. Hence, the judgment about possibility is not relevant at all, when living in fictional stories. Fiction does not convey beliefs in possibilities; instead, fiction does convey beliefs in actualities. What beliefs and what actualities? Precisely, neutralized beliefs in neutrally posited actualities. That is the point.

\section{Bibliography}

HuSSERL, E. (2000). Aktive Synthesen: Aus der Vorlesung 'Transzendentale Logik' 1920/21. Ergänzungsband zu 'Analysen zur passiven Synthesis'. Edited by Roland Breeur. Hua XXXI. The Hague: Kluwer.

- (1980). Phäntasie, Bildbewusstsein, Erinnerung. Zur Phänomenologie der anschaulichen Vergegenwartigungen. Texte aus dem Nachlass (18981925). Edited by Eduard Marbach. Hua XXIII The Hague: Martinus Nijhoff.

- (1977). Ideen zu einer reinen Phänomenologie und phänomenologischen Philosophie. Erstes Buch: Allgemeine Einführung in die reine Phänomenologie. 1. Halbband: Text der 1.-3. Auflage. Edited by Karl Schuhmann. Hua III-1. The Hague: Martinus Nijhoff.

- (1968). Zur Phänomenologie des inneren Zeitbewusstesens (18931917). Edited by Rudolf Boehm. Hua X. The Hague: Martinus Nijhoff.

KANT, I. (1998). Critique of Pure Reason. Translated by P. Guyer and A. Wood. Cambridge: Cambridge University Press.

KRIPKE, S. (1980). Naming and Necessity. Cambridge: Harvard University Press.

Ronen, R. (2005). «Are Fictional Worlds Possible?». In: M. Hoffman and P. Murphy. Essentials of the Theory of Fiction. Durham \& London: Duke University Press. 
PEDro M. S. Alves is Associate Professor (tenured) at the Faculty of Arts of the University of Lisbon. He also is senior-researcher at the Center of Philosophy of the University of Lisbon (CFUL). His main areas of interest are husserlian phenomenology, transcendental philosophy, philosophy of nature, and philosophy of law. He publishes regularly on these fields. His main monographic studies are: Studia Kantiana. Interpretação e Crítica (2009); Intersubjectividade e comunicação: Uma abordagem fenomenológica (2009); Subjectividade e Tempo na Fenomenologia de Husserl (2003); and Fenomenología del tiempo y de la percepción (2010). 